\title{
MODELO DE ENSINO HİBRIDOA A PERCEPÇÃO DOS ALUNOS EM RELAÇÃO A METODOLOGIA PROCRFGSISTA X METODOLOGIA TRADICIONAL
}

\author{
HYBRID TEACHING MODEL: STUDENTS' \\ PERCEPTION OF PROGRESSIVE \\ METHODOLOGY VS. TRADITIONAL \\ METHODOLOGY
}

João Batista da Silva joaobathista82@hotmail.com

Mestrando em Ensino de Ciências e Matemática pelo Instituto Federal de Educação, Ciência e Tecnologia do Ceará (Ceará/Brasil).

Diego de Oliveira Silva diegoelessar@yahoo.com.br

Mestrando em Ensino de Ciências e Matemática pelo Instituto Federal de Educação,

Ciência e Tecnologia do Ceará (Ceará/Brasil).

\section{Gilvandenys Leite Sales denyssales@gmail.com}

Doutor em Engenharia de Teleinformática pela Universidade Federal do Ceará (Ceará/Brasil).

Professor no Instituto Federal de Educação, Ciência e Tecnologia do Ceará (Ceará/Brasil). 


\section{RESUMO}

As tecnologias digitais, cada vez mais presentes na sociedade, têm causado mudanças comportamentais nos alunos. Pesquisas na área apontam algumas vantagens do uso de metodologias ativas, que utilizam recursos tecnológicos na situação formal de ensino, para atender às demandas dos alunos contemporâneos. Nesse sentido, o objetivo dessa pesquisa é aplicar uma metodologia progressista, que integra ensino presencial e online, denominada ensino híbrido, e investigar qual a percepção dos alunos sobre essa metodologia. A presente pesquisa apresenta um estudo de caso de natureza qualitativa, com alunos de uma turma de primeiro ano do Ensino Médio do Instituto Federal de Educação, Ciência e Tecnologia do Ceará (IFCE). Após a aplicação da metodologia proposta e dos recursos tecnológicos utilizados, são analisadas as respostas fornecidas pelos alunos sobre suas concepções a respeito dessa metodologia. Os resultados apontaram que, na opinião da maioria dos alunos, o uso da tecnologia digital não é necessário para melhorar a compreensão dos conteúdos de Física. Ademais, eles acreditam que compreendem melhor o conteúdo com aulas teóricas, preferindo assim, o modelo de ensino tradicional ao invés do modelo de ensino híbrido.

Palavras-chave: Ensino de física. Ensino híbrido. Metodologias ativas.

\section{ABSTRACT}

Digital technologies, increasingly present in society, have caused behavioral changes in students. Research in the area points to some advantages of the use of active methodologies, which use technological resources in the formal teaching situation, to meet the demands of contemporary students. In this sense, the objective of this research is to apply a progressive methodology, which integrates face-to-face and online teaching, called hybrid teaching, and investigate students' perceptions about this methodology. The present research presents a case study of a qualitative nature, with students from a first year high school class of the Federal Institute of Education, Science and Technology of Ceará (IFCE). After applying the proposed methodology and the technological resources used, the answers given by the students about their conceptions about this methodology are analyzed. The results showed that, in the opinion of most students, the use of digital technology is not necessary to improve the understanding of physics contents. In addition, they believe that they better understand the content with theoretical classes, preferring instead the traditional teaching model instead of the hybrid teaching model.

Keywords: Physics education. Hybrid teaching. Active Methodologies. 


\section{INTRODUÇÃo}

As Tecnologias Digitais da Informação e Comunicação (TDIC) já fazem parte da vida da maioria dos brasileiros, principalmente devido ao desenvolvimento acelerado dos dispositivos móveis (celulares, tablets, smartphones, computadores, entre outros). Com a chegada e a popularidade desses dispositivos na maior parte das camadas sociais brasileiras, o acesso à informação e à comunicação foi facilitado. Além disso, o desenvolvimento de aplicativos para esses dispositivos proporcionou uma maior intensidade do fluxo de informações em massa. $O$ uso desses dispositivos móveis tornou-se um hábito, sendo quase impossivel não ver alguém, a qualquer hora e lugar (no ônibus, na praia, na serra, no restaurante, na escola, etc.) manipulando esses aparelhos digitais. Tendo em vista o aumento cada vez mais expressivo da frequência com que esses usuários interagem com a tecnologia, independente de onde estejam, esses lugares foram transformados em um ambiente onipresente (PRENSKY, 2001).

Os dispositivos móveis, principalmente os celulares, passaram a fazer parte da vida dos alunos, tornando-se um acessório inseparável. Portanto, o professor não pode ignorar esse fenômeno singular. Ora, "se, no nosso dia a dia, os dispositivos móveis são inseparáveis da nossa vivência, porque não os usar em contexto educativo e formativo?" (CARVALHO, 2015, p. 9).

De acordo com Dellos (2015) as TDIC proporcionam aos professores a possibilidade de utilizar diferentes recursos durante a instrução da sala de aula, e aos alunos a oportunidade de desenvolver capacidades e habilidades. Conforme Bueno e Ritzel (2013), nos últimos anos o computador passou a ser utilizado como uma ferramenta educacional capaz de contribuir na construção do conhecimento pelo próprio aluno.

Como "o uso de tecnologias, já faz parte do cotidiano dos alunos, a escola tem que se aproximar desse cotidiano, para avançar na sua missão" (SILVA et al., 2015). Todavia, incorporar adequadamente o uso das tecnologias em sala de aula é uma tarefa desafiadora para os professores, o que significa que os educadores precisam variar os métodos de ensino para criar experiências de aprendizagem para cada aluno, pois "todos os alunos são capazes de aprender e têm diferentes estilos de aprendizagem" (DELLOS, 2015, p. 49).

Considerando o uso das TDIC no contexto escolar, Moreira (2012) sugere que no processo de ensino, quando for se referir ao termo "sala de aula", é mais aconselhável fazer uso do termo "situação formal de ensino" que pode acontecer tanto em sala de aula (presencial) quanto nos ambientes virtuais. Atualmente, alguns pesquisadores (CARVALHO, 2015; WANG, 2014) investigam o uso das TDIC como recurso didático para ser utilizado em sala de aula no suporte ao processo de ensino e aprendizagem. Carvalho (2015) enfatiza que o fato dos alunos estarem sempre em mãos com um smartphone, ou um 


\section{CONHECIMENTO

tablet, potencializa e possibilita que o processo de aprendizagem possa ser feito também fora da escola, em qualquer lugar e a qualquer hora, caracterizando assim uma aprendizagem móvel (mobile learning). Ampliando, assim, tanto a aprendizagem através da integração de diferentes contextos em que o aluno está inserido, quanto pelo rompimento das fronteiras espaço-temporais historicamente estabelecidas na sala de aula tradicional.

Vale destacar que há necessidade de orientações sobre o uso desses dispositivos em contextos educativos, para que esse recurso proporcione resultados de acordo com o planejado pelo professor. Wang (2014) destaca que o uso da tecnologia em sala de aula, de imediato, resulta em entusiasmo tanto para os professores quanto para os alunos, cuja maioria tem seus próprios dispositivos digitais móveis que já dominam. 0 domínio e a facilidade com que os alunos interagem, principalmente com os dispositivos móveis, são justificados pelo fato deles serem nativos digitais (PRENSKY, 2001), caracterizados por serem imediatistas, com habilidades excepcionais de alfabetização visual em um mundo cujo fluxo informacional é intenso e célere.

De acordo com Prensky (2001), os modelos de pensamento dos alunos contemporâneos foram modificados, por isso eles pensam e processam as informações de modo bem diferentes das gerações anteriores.

Considerando a efervescência comportamental, fruto do impacto do rápido avanço tecnológico nas últimas décadas, e enfatizando a atuação predominante das tecnologias nos ambientes educativos movidos pela convicção de sua necessidade, urge um posicionamento por parte da escola capaz de atentar para as demandas culturais desses novos alunos, que exigem múltiplos fluxos de informação e preferem raciocínio indutivo, rápido e com respostas imediatas (ECK, 2006). Dessa forma, a escola deve proporcionar a interação desses jovens com as TDIC e se aproximar do universo dos seus alunos para se tornar um locus de prazer e construção de sentido (ALVES, 2012).

Ao tratar das perspectivas tecnológicas brasileiras para o Ensino Fundamental e Médio de 2012 a 2017, Johnson et al. (2012) apontam que o modelo de educação vigente no Brasil tem que se modificar para dar conta da inclusão do aprendizado online, do aprendizado híbrido e dos modelos de aprendizagem colaborativa. 0 aprendizado online é proporcionado pelo acesso através da internet, que possibilita aos alunos estudar e aprender sempre que quiserem e onde estiverem. Esse desafio leva a refletir cada vez mais sobre o papel dos professores e educadores contemporâneos.

Os métodos transmissivos de ensino, praticados pela maioria das instituições escolares, não são mais capazes, por si só, de atender às demandas de indivíduos que incorporam cada vez mais as características da cultura digital, como o fácil acesso à informação através das tecnologias digitais (FARDO, 2013, p. 17). 
No fragmento acima, Fardo (2013) destaca que os métodos de ensino tradicionais baseados apenas na premissa de que a transmissão do conhecimento deve partir apenas do professor para os alunos, ignorando o novo contexto social em que esse aluno está inserido, não dão mais conta das demandas dos novos alunos. Isso contribui para que tais métodos sejam cada vez mais questionados e revisados no âmbito acadêmico.

Nesse sentido, Johnson et al. (2012) descrevem as tendências educacionais mais importantes identificadas nos projetos de pesquisa do New Media Consortium (NMC) ${ }^{1}$, dentre elas estão o ensino híbrido e colaborativo.

As tecnologias destacadas no NMC Horizon Project estão inseridas em um contexto contemporâneo que reflete a realidade do tempo atual, tanto na esfera da educação quanto do mundo. Para garantir esta perspectiva, cada conselho pesquisa, identifica e classifica tendências-chave que estão atualmente afetando a prática do ensino/ aprendizado nas escolas e utilizam essa reflexão como um guia para seu trabalho de prever e planejar a implantação dessas tecnologias emergentes em qualquer região ou setor em foco. Essas tendências surgiram através de uma extensa análise dos artigos, entrevistas, trabalhos atuais e de novas pesquisas. Uma vez identificada, a lista de tendências é classificada de acordo com a importância do impacto que elas possivelmente terão no ensino nos próximos cinco anos (JOHNSON et al., 2012, p. 19)

Moran (2015) destaca que as instituições educacionais em sintonia com as mudanças normalmente escolhem dois caminhos: a) um mais amplo, com mudanças profundas que propõem modelos mais inovadores, disruptivos, sem disciplinas, muitas vezes sendo necessário redesenhar todo o projeto, tanto os espaços físicos, quanto as metodologias; e b) outro voltado para as mudanças progressivas, caracterizado por ser mais suave, por manter o modelo curricular predominante, priorizando o envolvimento maior do aluno, com metodologias ativas. Como é o caso, por exemplo, do modelo de ensino híbrido, caracterizado por proporcionar ao aluno flexibilidade e autonomia, onde ele possa controlar o tempo, lugar, modo, ritmo dos estudos (CHRISTENSEN; HORN; STAKER, 2013), aumentando, assim, as possibilidades de o aluno aprender tanto dentro quanto fora do espaço formal de ensino.

Considera-se, então, que o modelo de ensino híbrido, auxiliado pelo uso das tecnologias, pode potencializar os processos de aprendizagem em que o aluno passa a ser ativo e autônomo. Mas, qual será a opinião dos alunos com relação a essas mudanças tão relevantes? Nesse sentido, o objetivo dessa

\footnotetext{
1 Uma comunidade internacional de especialistas em tecnologia educacional, que diariamente investigam e trabalham com o uso
} de tecnologias, cujo objetivo é moldar o futuro da aprendizagem em grupos de reflexão, laboratórios e centros de investigação. 
pesquisa é aplicar uma metodologia progressista, que integra ensino presencial e online, denominada ensino híbrido, e investigar qual a percepção dos alunos sobre essa metodologia.

Este artigo é organizado da seguinte forma, na seção 1 foi realizada uma revisão da literatura e a identificação da problemática, na seção 2 é abordado sobre as características do ensino híbrido, na seção 3 apresenta-se a metodologia aplicada, na seção 4 analisa-se e discute-se os resultados e, por fim, na seção 6 são apresentadas as considerações finais.

\section{ENSINO HÍBRIDO}

O ensino híbrido é um programa de educação formal no qual o aluno aprende, pelo menos em parte, por meio do ensino online, e cuja característica é a conexão entre o presencial e o online para oferecer uma experiência de educação integrada. Ou seja, "os estudantes continuam o estudo de onde pararam quando trocam de uma modalidade" (CHRISTENSEN; HORN; STAKER, 2013, p. 7). Um engano comum a respeito desse modelo de ensino híbrido é pensar que ele é bom, enquanto o modelo de ensino tradicional é ruim, isso é um equívoco.

0 modelo de ensino tradicional foi, durante anos, fundamental para o desenvolvimento científico e tecnológico da sociedade. Porém, com o avanço tecnológico houve uma mudança comportamental radical, onde os alunos contemporâneos mudaram e já não são os mesmos para os quais o sistema educacional foi criado (PRENSKY, 2001). Nesse caso, o modelo de ensino tradicional já não é mais capaz de atender às demandas dos nativos digitais que incorporam cada vez mais as características da cultura digital tendo fácil acesso à informação (FARDO, 2013). De acordo com Prensky (2001, p. 1) "é bem provável que as mentes de nossos alunos tenham mudado fisicamente - e sejam diferentes das nossas - sendo resultado de como eles cresceram". Conforme Johnson et al. (2012) o ensino híbrido é a primeira das dez tendências de ensino apresentada no NMC, identificadas como impulsionadoras da adoção de tecnologias no Ensino Fundamental e Médio do Brasil durante o período que vai de 2012 até 2017 . 0 quadro abaixo sintetiza as tendências na ordem em que foram classificadas pelo conselho. 


\section{Quadro 1 - Síntese das tendências apresentada pela NMC}

\begin{tabular}{|c|c|}
\hline 10 & $\begin{array}{l}\text { Os paradigmas do ensino estão se modificando para incluir modelos de aprendizado online, } \\
\text { híbridos e colaborativos. }\end{array}$ \\
\hline $2 \circ$ & $\begin{array}{l}\text { A abundância de recursos e relacionamentos aos quais a internet facilitou o acesso está nos } \\
\text { desafiando cada vez mais a revisitar nossos papéis como educadores. }\end{array}$ \\
\hline $3 \circ$ & $\begin{array}{l}\text { As pessoas esperam poder trabalhar, aprender e estudar sempre que quiserem e de onde } \\
\text { estiverem. }\end{array}$ \\
\hline 40 & $\begin{array}{l}\text { As escolas estão cada vez mais explorando tecnologias que permitem que professores e } \\
\text { alunoscolaborem de forma mais eficiente. }\end{array}$ \\
\hline $5^{\circ}$ & $\begin{array}{l}\text { A crescente disponibilidade de banda larga modificará de forma dramática os comportamentos } \\
\text { dos usuários durante o ensino, aprendizado e pesquisa durante os próximos cinco anos. }\end{array}$ \\
\hline $6 \circ$ & $\begin{array}{l}\text { As tecnologias que utilizamos estão cada vez mais baseadas na nuvem e nossas noções de } \\
\text { suporte de TI são descentralizadas. }\end{array}$ \\
\hline 70 & As pessoas têm necessidade de compartilhar - muitas vezes publicamente. \\
\hline 80 & Cada vez mais estudantes querem usar sua própria tecnologia para o aprendizado. \\
\hline $9 \circ$ & $\begin{array}{l}\text { Existe uma nova ênfase na sala de aula em relação a um aprendizado mais ativo e mais baseado } \\
\text { em desafios. }\end{array}$ \\
\hline 10 은 & Os computadores, como os conhecemos, estão em processo de uma sólida reinvenção. \\
\hline
\end{tabular}

\section{Fonte: Adaptado de Johnson et al. (2012)}

De acordo com Johnson et al. (2012), para se fazer o levantamento sobre tendências que envolvem o uso de tecnologias no Ensino Fundamental e Médio brasileiro, especialistas passaram uma boa quantidade de tempo pesquisando e discutindo o aprendizado e o pensamento criativo. As tendências refletem distintamente os impulsionadores com os quais as escolas no Brasil se depararão nos próximos anos, dentre eles o modelo de ensino híbrido.

O modelo de ensino híbrido, por sua vez, não é paradoxal nem dicotômico ao ensino tradicional. O que esse modelo se propõe é pensar a educação como um processo contínuo de aprendizagem, combinando espaços físicos da sala de aula e os múltiplos espaços do cotidiano, incluindo os digitais (MORAN, 2015), para possibilitar que o aluno aprenda tanto dentro quanto fora do espaço formal de ensino, de forma mais flexível, a partir das necessidades e contribuições do grupo. 0 importante nesse modelo é que o ensino seja mais dependente da capacidade criativa do aluno, o qual passará a ser coautor de seu processo educativo.

Por isso a educação formal é cada vez mais blended, misturada, híbrida, porque não acontece só no espaço físico da sala de aula, mas nos múltiplos espaços do cotidiano, que incluem os digitais. 
Em muitas escolas, o ensino híbrido está emergindo como uma inovação sustentada em relação à sala de aula tradicional. Esta forma híbrida é uma tentativa de oferecer "o melhor de dois mundos" - isto é, as vantagens da educação online combinadas com todos os benefícios da sala de aula tradicional. Por outro lado, outros modelos de ensino híbrido parecem ser 'disruptivos'em relação às salas de aula tradicionais. Eles não incluem a sala de aula tradicional em sua forma plena [...] Os modelos de ensino híbrido que seguem o padrão dos híbridos estão numa trajetória sustentada em relação à sala de aula tradicional (CHRISTENSEN; HORN; STAKER, 2013, p. 3-4).

Para os autores, o ensino híbrido deve ser estabelecido e construído sobre o modelo de ensino tradicional, de modo a oferecer melhorias, mas sem romper com ele, permitindo que os alunos tanto aprendam online quanto na sala de aula física com instrução presencial. Ademais, as matérias podem ser conectadas para oferecer uma experiência de educação integrada, onde o aluno possa controlar o tempo, lugar, modo e ritmo do estudo, ou seja, o aluno ser o maestro de sua aprendizagem.

De acordo com Moran (2015) os métodos tradicionais de ensino faziam sentido quando o acesso à informação era difícil, no entanto, a democratização do acesso às tecnologias, possibilitou a integração de todos os espaços e tempos, tanto no mundo real quanto no mundo virtual. É importante destacar que "não são dois mundos ou espaços, mas um espaço estendido, uma sala de aula ampliada, que se mescla, hibridiza constantemente" (MORAN, 2015, p. 16).

Ao analisar a evolução tecnológica dos computadores e suas aplicações no ensino, Sales (2005) faz um paralelo entre os modelos de ensino fundamentados no paradigma tradicional/instrucionista e o paradigma construtivista/construcionista. O Construtivismo está fundamentado na teoria de Jean Piaget (1896-1980) que tenta explicar a construção do conhecimento de um ponto de vista biológico, considerando o desenvolvimento de estruturas cognitivas pelo sujeito no decorrer do seu desenvolvimento. O Construcionismo de Seymour Papert está baseado na teoria piagetiana, acrescentando a influência do coletivo, na construção do conhecimento, ou seja, como os indivíduos elaboram e constroem o conhecimento coletivamente. Vale destacar que ambas as teorias têm como pressuposto que a influência do ambiente externo contribui para o processo de aprendizagem. A seguir, no quadro 2, estão sintetizadas as características dos dois modelos de ensino: instrucionista e construcionista. 
Quadro 2 - Síntese dos Modelos Instrucionista e Construcionista

\begin{tabular}{|c|c|c|}
\hline & INSTRUCIONISTA & CONSTRUCIONISTA \\
\hline CONHECIMENTO & $\begin{array}{l}\text {-Adquirido por meio da instruçăo. } \\
\text {-A única maneira de melhorar o } \\
\text { conhecimento do aluno sobre } \\
\text { determinado tópico é ensinar mais } \\
\text { sobre aquele tópico. }\end{array}$ & $\begin{array}{l}\text {-Énfase na construçăo do conhecimento e } \\
\text { năo na instruçăo. } \\
\text {-A busca do conhecimento específico que } \\
\text { o aluno precisa è que o ajudará a obter } \\
\text { mais conhecimento. }\end{array}$ \\
\hline ENSINO & $\begin{array}{l}\text {-Dá-se no sentido: Computador- } \\
\text { Software-Aluno. } \\
\text {-Por meio do computador o aluno é } \\
\text { instruido e pode adquirir conceitos } \\
\text { sobre qualquer área. }\end{array}$ & $\begin{array}{l}\text {-Dá-se no sentido: Aluno-Software- } \\
\text { Computador. } \\
\text { - Tem por objetivo ensinar de forma a obter } \\
\text { a maior aprendizagem com um minimo de } \\
\text { ensino. }\end{array}$ \\
\hline APRENDIZAGEM & $\begin{array}{l}\text {-Aprendizagem centrada no ensino. } \\
\text { - o computador comanda a } \\
\text { aprendizagem do aluno. } \\
\text {-A via que conduz a uma melhor } \\
\text { aprendizagem é o aperfeiçoamento } \\
\text { da instruçăo. }\end{array}$ & $\begin{array}{l}\text { - Centra-se na aprendizagem e năo no } \\
\text { ensino. } \\
\text {-A aprendizagem ocorre em razäo do } \\
\text { aluno estar executando uma tarefa } \\
\text { mediada pelo computador. } \\
\text { - O aluno gerencia seu próprio processo de } \\
\text { aprendizagem. } \\
\text {-Visa a desenvolver a capacidade } \\
\text { matética }{ }^{5} \text {. }\end{array}$ \\
\hline PROFESSOR & $\begin{array}{l}\text {-Repassador do conhecimento e } \\
\text { instruçōes. } \\
\text {-Tem o papel de especialista de } \\
\text { conteúdos. }\end{array}$ & $\begin{array}{l}\text { - Criador de ambientes de aprendizagem. } \\
\text {-Agente facilitador do processo de } \\
\text { desenvolvimento cognitivo do aluno. } \\
\text {-Mediador da interação aluno-computador. } \\
\text { - Tem por funça a investigação da } \\
\text { estrutura mental do aluno. }\end{array}$ \\
\hline ALUNO & $\begin{array}{l}\text {-Receptor passivo do conhecimento. } \\
\text {-Consultor de instruçōes. }\end{array}$ & $\begin{array}{l}\text { - Construtor de seu próprio conhecimento. } \\
\text {-Gerenciador da informaçăo, da soluçăo } \\
\text { de problemas e da aprendizagem } \\
\text { independente. }\end{array}$ \\
\hline $\begin{array}{l}\text { O USO DO } \\
\text { COMPUTAD }\end{array}$ & $\begin{array}{l}\text {-Máquina de ensinar (instruçäo } \\
\text { programada). } \\
\text {-Informatizaçäo dos métodos de } \\
\text { ensino tradicionais. } \\
\text {-É introduzido na Escola como } \\
\text { disciplina curricular, è o aprender } \\
\text { sobre computadores. }\end{array}$ & $\begin{array}{l}\text { - Ferramenta intelectual para promover a } \\
\text { aprendizagem. } \\
\text { - Meio de transferência do controle do } \\
\text { processo de ensino do professor para o } \\
\text { aluno. } \\
\text {-Veículo auxiliar no processo de } \\
\text { expressäo de nosso pensamento e da } \\
\text { reflexäo. }\end{array}$ \\
\hline
\end{tabular}

\section{Fonte: Sales (2005, p. 18)}

A partir das informações contidas no quadro acima, percebe-se a aproximação do ensino construcionista com o modelo de ensino híbrido. Entre as principais características nos modelos observase o uso do computador, ou das TDIC, como recurso didático, em que o aluno interage com a ferramenta na construção do conhecimento, e não simplesmente absorve a informação de forma passiva. Além disso, observa-se que o desafio do professor é criar um ambiente educativo em que o aluno possa gerenciar seu próprio processo de aprendizagem, construindo o conhecimento de forma independente e ativa, tornando-se, portanto, autor de sua própria aprendizagem (SALES, 2005). 


\section{METODOLOGIA}

Esta é uma pesquisa de natureza qualitativa, por se mostrar mais adequada a este tipo de investigação. Quanto aos procedimentos técnicos, foi realizado um estudo de caso, que segundo Yin (2001), é caracterizado como sendo um tipo de investigação empírica utilizada para observar um dado fenômeno em seu contexto real.

A investigação adotou como instrumentos de coleta de dados o questionário, cujas questões visavam favorecer a expressão de argumentos produzidos pelos estudantes. 0 questionário foi estruturado utilizando a escala Likert de seis pontos em cada assertiva: 'Concordo muito fortemente' (CMF), 'Concordo fortemente' (CF), 'Concordo' (C), 'Discordo' (D), 'Discordo fortemente' (DF) e 'Discordo muito fortemente' (DMF).

A escolha desses instrumentos se justifica pelo fato de permitir uma coleta de dados que seja potencialmente significativa para atingir o objetivo proposto nesse trabalho e proporcionar maiores esclarecimentos sobre a percepção dos alunos.

O questionário foi composto por vinte assertivas, que foram agrupadas em quatro categorias conceituais, cujo propósito foi investigar a percepção dos alunos em relação:

a) ao perfil do professor, sua pontualidade, assiduidade e domínio do conteúdo ensinado.

b) às metodologias de ensino/aprendizagem empregada pelos professores como: métodos de ensino, compreensão dos conteúdos abordados e recursos didáticos utilizados pelo professor.

c) à interação professor-aluno: incentivo à participação dos alunos e respeito.

d) ao processo avaliativo: nível de avaliação adequado e métodos de avaliação.

Também foi destinado um espaço aberto no questionário para que os alunos pudessem escrever de forma livre sua opinião sobre as metodologias e sobre os professores, destacando os pontos positivos e negativos de cada metodologia.

A pesquisa foi realizada durante o segundo semestre de 2016 em uma turma de Ensino Médio do curso técnico integrado em Química do Instituto Federal de Educação, Ciência e Tecnologia do Ceará (IFCE). 0 universo da pesquisa é representado por 35 alunos. Os investigados apresentam em comum a idade média entre 14 e 16 anos, além disso, todos eles têm aproximadamente o mesmo nível de conhecimento, pois passaram por processo seletivo composto por prova objetiva de múltipla escolha e uma redação.

O conteúdo de Física abordado pelos professores foi Mecânica Clássica: Trabalho e Energia Cinética; Energia Potencial, Energia Mecânica e Conservação de Energia; Impulso e Quantidade de Movimento; Conservação da Quantidade de Movimento e Choques. 
Todas as aulas foram presenciais com algumas atividades sendo realizadas online, contando com a participação de dois professores, o primeiro foi denominado de professor $A$, e o segundo, Professor B. $O$ ensino do conteúdo foi dividido em duas etapas, e cada etapa ficou sob a responsabilidade de um professor.

Na primeira etapa, o Professor A ministrou as aulas utilizando-se de metodologias progressistas, nesse caso o ensino híbrido. A sequência estabelecida dos conteúdos utilizada pelo professor foi a referenciada no livro-texto adotado. Já os recursos didáticos utilizados foram os mais diversos possíveis: computadores, projetor, ambiente virtual de aprendizagem (AVA), Objeto de Aprendizagem (OA), quizzes, fórum de discussões, atividades experimentais, quadro, pincel e listas de exercícios. Para isso, o professor fez uso de um ambiente virtual de aprendizagem (AVA) denominado Help Class Online, customizado a partir da plataforma Moodle, disponibilizado no endereço eletrônico http://www.helpclassonline.com.br/ moodle/. Além da realização de experimentos em sala de aula e da utilização de simulações e vídeos disponiveis na internet, buscou-se uma abordagem que valorizasse a interação dos alunos com o conteúdo.

Os alunos tiveram acesso à plataforma onde foi mantido um banco de dados com as notas e frequências dos estudantes, que poderiam acessá-los a qualquer momento. Um fórum foi disponibilizado para que os alunos trocassem informações a respeito do conteúdo visto em sala. As animações e Objetos de Aprendizagem (OAs) utilizados, apesar de não terem sido hospedadas na plataforma, tiveram seus endereços disponibilizados.

Além disso, foram realizadas simulações experimentais, com simuladores virtuais ancorados na plataforma PROATIVA (http://www.proativa.vdl.ufc.br), contendo atividades para guiar sua utilização pelos alunos. Foram realizadas também atividades experimentais reais, para tentar buscar uma abordagem que valorizasse a interação dos alunos com o conteúdo, de modo que pudessem interagir com Objeto de Aprendizagem (OA) para construir seu próprio conhecimento.

Para verificar as evidências de aprendizagem do aluno, o professor A realizou uma avaliação formativa. Para isso ele utilizou vários instrumentos, inclusive o teste tradicional, com questões de múltipla escolha envolvendo a relação entre conceitos e a formalização matemática, porém, cada um com um peso diferente. A nota da etapa foi composta pela média aritmética da nota das atividades e a nota do teste. Para compor a nota, o professor solicitou aos alunos que fossem realizadas várias atividades, tanto na sala de aula quanto no ambiente virtual. As atividades virtuais foram compostas por um fórum sobre as Leis de Newton (10\%), uma atividade experimental sobre força elástica e molas (15\%) e uma atividade com o OA "Gangorra Interativa" (15\%), envolvendo os conceitos de momento de uma força. Além disso, 
foram realizados dois quizzes, cada um permanecendo aberto por dois dias. Um quiz abordando o tema Estática (30\%), e o outro sobre as aplicações das Leis de Newton (30\%). Os alunos tinham direito a realizar duas tentativas para responder ao teste e a nota final seria a mais alta dentre as duas.

A plataforma moodle possibilitou a utilização de uma série de ferramentas na elaboração de testes online. Entre elas utilizou-se a "randomização" de variáveis, que proporcionou ao professor a escolha de um parâmetro para cada questão, com um valor aleatório escolhido dentro de um intervalo pré-estabelecido, onde, para cada aluno, embora realizando a mesma questão, a ordem das alternativas era diferente. Os quizzes, utilizados como atividade avaliativa, contaram com 5 questões de variável randomizada, 2 de múltipla escolha, 1 de associação e 2 questões com respostas abertas.

A segunda etapa foi conduzida pelo Professor B, que utilizou o modelo de ensino tradicionalista (instrucionista e conteudista) vinculado ao processo histórico e cultual da educação brasileira, no ensino do conteúdo específico de Física. A metodologia foi voltada para a formalização matemática e para a resolução de exercícios, hierarquizado por graus de dificuldade, seguindo a lógica sequencial do livro didático.

A sequência estabelecida pelo professor teve como referência o livro-texto adotado. Nesse caso, a cada duas aulas teóricas expositivas para explicação do conteúdo, o professor utilizou a mesma quantidade de aulas para que o aluno pudesse sedimentar o conhecimento através da resolução de uma lista de exercícios.

Os recursos utilizados foram quadro, pincel e listas de exercícios disponibilizadas no sistema acadêmico da própria instituição (http://qacademico.ifce.edu.br/).

Para verificar as evidências de aprendizagem do aluno, foi realizada uma avaliação somativa. 0 instrumento utilizado foi o teste tradicional, com questões de múltipla escolha envolvendo a relação entre conceitos e a formalização matemática.

\section{RESULtados e discussão}

Nesta seção serão apresentados e discutidos os resultados obtidos com a aplicação dos questionários, considerando as quatro categorias em que as assertivas foram classificadas.

Nessa primeira categoria, o questionário foi direcionado para verificar qual a percepção do aluno com relação ao perfil do professor, no tocante à segurança e domínio do conteúdo ministrado. Os resultados mostram que, de acordo com a percepção dos alunos, há uma aproximação significativa entre o aparente domínio do conteúdo pelos dois professores (TABELA 1). De acordo com os resultados, a discordância da assertiva foi apenas de $5 \%$, tanto do professor $A$, quanto do professor $B$, o que evidencia que na visão dos 
alunos os dois professores aparentemente apresentam a mesma segurança aos conteúdos específicos da disciplina. Carvalho e Gil Perez (2001) defendem a ideia de que para o professor fazer uma crítica à outra metodologia de ensino, seja ela tradicional ou progressista, ele precisa dominar os conhecimentos conceituais e metodológicos específicos de sua área.

Conforme a tabela 1, ambos os professores apresentaram o mesmo nivel de conhecimento, portanto este não é um fator que possa interferir na opinião dos alunos a respeito da metodologia aplicada. É importante destacar que, caso um professor, aparentemente, apresentasse mais domínio do que o outro, poderia haver interferência nas opiniões.

A segunda categoria direcionou o questionário para investigar qual a percepção do aluno com relação ao método de ensino do professor e a utilização de recursos didáticos como recurso facilitador para a compreensão do conteúdo (Tabela 2).

Tabela 1 - Síntese das percepções dos alunos a respeito do domínio do conteúdo pelo professor

\begin{tabular}{|c|c|c|c|c|c|c|}
\hline Assertivas & CMF & CF & C & D & DF & DMF \\
\hline $\begin{array}{l}\text { O Professor A apresenta segurança no conteúdo } \\
\text { ministrado. }\end{array}$ & $78,95 \%$ & $10,53 \%$ & $5,26 \%$ & $5,26 \%$ & $0,00 \%$ & $0,00 \%$ \\
\hline $\begin{array}{c}\text { O Professor B apresenta segurança no conteúdo } \\
\text { ministrado. }\end{array}$ & $61,11 \%$ & $22,22 \%$ & $11,11 \%$ & $5,56 \%$ & $0,00 \%$ & $0,00 \%$ \\
\hline
\end{tabular}

\section{Fonte: Elaborada pelo autor}

Tabela 2 - Síntese das percepções dos alunos a respeito dos recursos didáticos

\begin{tabular}{|c|c|c|c|c|c|c|}
\hline Assertivas & CMF & CF & C & D & DF & DMF \\
\hline $\begin{array}{l}\text { O Professor A adota formas e recursos didáticos adequados ao } \\
\text { ensino. }\end{array}$ & $42,11 \%$ & $26,32 \%$ & $10,53 \%$ & $21,05 \%$ & $0,00 \%$ & $0,00 \%$ \\
\hline $\begin{array}{l}\text { O Professor B adota formas e recursos didáticos adequados ao } \\
\text { ensino. }\end{array}$ & $36,84 \%$ & $52,63 \%$ & $5,26 \%$ & $5,26 \%$ & $0,00 \%$ & $0,00 \%$ \\
\hline $\begin{array}{c}\text { Conseguir compreender melhor os assuntos abordados quando fiz } \\
\text { os quizzes online fora da escola. }\end{array}$ & $10,53 \%$ & $15,79 \%$ & $31,58 \%$ & $15,79 \%$ & $5,26 \%$ & $21,05 \%$ \\
\hline $\begin{array}{c}\text { Conseguir compreender melhor os assuntos abordados quando fiz } \\
\text { experimentos na sala de aula. }\end{array}$ & $55,56 \%$ & $16,67 \%$ & $11,11 \%$ & $11,11 \%$ & $0,00 \%$ & $5,56 \%$ \\
\hline $\begin{array}{c}\text { Não é necessária a utilização de tecnologia digitais para melhorar } \\
\text { a compreensão da Física }\end{array}$ & $11,11 \%$ & $16,67 \%$ & $27,78 \%$ & $5,56 \%$ & $22,22 \%$ & $16,67 \%$ \\
\hline $\begin{array}{c}\text { Não é necessária a utilização de aparatos experimentais reais } \\
\text { para melhorar a compreensão da Física. }\end{array}$ & $0,00 \%$ & $10,53 \%$ & $10,53 \%$ & $10,53 \%$ & $31,58 \%$ & $36,84 \%$ \\
\hline Compreendo melhor assistindo aulas teóricas & $42,11 \%$ & $15,79 \%$ & $31,58 \%$ & $10,53 \%$ & $0,00 \%$ & $0,00 \%$ \\
\hline
\end{tabular}

Fonte: Elaborada pelo autor 
A partir da assertiva que questionou sobre os recursos didáticos adotados pelos professores, é possivel perceber a discordância, uma tênue preferência pela metodologia do professor $B$, pois 5,26\% discordaram dos recursos didáticos, enquanto a discordância em relação à metodologia do professor $A$ foi de $21,05 \%$. A maior divergência de opiniões se concentrou na avaliação dos quizzes. A hipótese para a rejeição aos quizzes pode ser a curva de aprendizado necessária para utilizar o AVA.

Verificou-se que apesar dos alunos apresentarem muita familiaridade com algumas ferramentas tecnológicas (tablets, smartphones) e demonstrarem o domínio de outras ferramentas de comunicação como o WhatsApp, foi evidenciado dificuldades em manipular as ferramentas e os recursos disponiveis no AVA. Conforme Wang (2014), o uso da tecnologia apenas resulta em entusiasmo imediato, tanto para os professores quanto para os alunos, quando eles dominam o uso desses dispositivos digitais.

Além disso, é importante destacar que o fato dos alunos sempre terem em mãos um dispositivo móvel poderá potencializar o processo de ensino, não garantirá um melhor rendimento na aprendizagem (CARVALHO, 2015). Nesse sentido, para obter um bom resultado nas avaliações online, é necessário que os alunos tanto dominem o conteúdo específico, quanto saibam manipular as ferramentas digitais.

Portanto, foi evidenciado que na percepção dos alunos, eles preferemo sistema de avaliação tradicional, que já é familiar, e pode contribuir para um melhor aproveitamento nas provas do Exame Nacional do Ensino Médio - ENEM. Esse pressuposto também é confirmado quando 89,47\% dos alunos explicitam que compreende melhor o conteúdo assistindo nas aulas teóricas, e 21,06\% afirmam que não é necessária a utilização de aparatos experimentais reais para melhorar a compreensão da Física. Ademais, a divergência de opiniões sobre a necessidade de utilização de tecnologia digitais para melhorar a compreensão de Física foi bastante acentuada, dividindo visivelmente as opiniões dos alunos, sendo que 55,56\% deles acreditam que a utilização de tecnologias digitais não é necessária para o aprendizado de Física.

Na terceira categoria, o questionário foi direcionado para pesquisar a percepção dos alunos com relação à interação professor-aluno como construto motivacional para melhorar o aprendizado. Para Schroeder (2007, p. 90), o ensino "necessita não somente de desenvolver habilidades cognitivas dos estudantes, mais também seus valores pessoais, a capacidade de perseverar, de lidar com frustações (autocontrole) e refletir sobre suas ações e expectativas, ou seja, desenvolver suas habilidades afetivas, uma vez que o aprendizado necessita de um motivador".

Nesse sentido, verificou-se que, tanto a metodologia usada pelo professor $A$, quanto a usada pelo professor B, estimularam a participação dos alunos, não havendo discordância significativa por nenhum deles. Apenas, o professor A foi mais bem avaliado com 73,68\% no ponto "Concordo Muito Fortemente", contra 52,63\%. Também foi evidenciada uma diferença tênue na assertiva que abordou o respeito do 
professor em relação ao aluno, onde 10,53\% discordaram que exista um clima de respeito. A tabela abaixo sintetiza as respostas dos alunos.

Tabela 3 - Síntese das percepções dos alunos a respeito interação professor-aluno

\begin{tabular}{|c|c|c|c|c|c|c|c|}
\hline Assertivas & CMF & CF & C & DF & DMF \\
\hline O Professor A estimula a participação do Aluno nas aulas. & $73,68 \%$ & $10,53 \%$ & $15,79 \%$ & $0,00 \%$ & $0,00 \%$ & $0,00 \%$ \\
\hline O Professor B estimula a participação do Aluno nas aulas. & $52,63 \%$ & $31,58 \%$ & $15,79 \%$ & $0,00 \%$ & $0,00 \%$ & $0,00 \%$ \\
\hline Existe clima de respeito na relação do Professor A com o aluno & $84,21 \%$ & $5,26 \%$ & $10,53 \%$ & $0,00 \%$ & $0,00 \%$ & $0,00 \%$ \\
\hline Existe clima de respeito na relação do Professor B com o aluno & $57,90 \%$ & $15,79 \%$ & $15,79 \%$ & $10,53 \%$ & $0,00 \%$ & $0,00 \%$ \\
\hline
\end{tabular}

\section{Fonte: Elaborada pelo autor}

A quarta categoria foi direcionada para investigar qual a percepção do aluno com relação aos métodos e níveis de avaliação utilizados pelos professores.

Com relação ao nível da avaliação, 100\% da turma respondeu que achou o nível de prova do professor A mais justo e adequado, enquanto o método de avaliação do professor $B$ teve 5,26\% de rejeição.

Porém, a respeito dos instrumentos utilizados para avaliação dividiu-se bastante a opinião da turma, apontando uma preferência pelo instrumento utilizado pelo professor B (o teste). Sendo que, 78,96\% dos alunos concordaram que o instrumento utilizado pelo professor B permitiu uma melhor avaliação, enquanto apenas $57,89 \%$ dos alunos concordaram com os instrumentos utilizados pelo professor $A$. De acordo com as respostas, pode-se perceber uma determinada rejeição, por parte dos alunos, em relação à utilização de instrumentos digitais de avaliação, acreditando que apenas a prova escrita ainda é melhor instrumento para verificar as evidências de aprendizagem.

\section{CONSIDERAÇÕES FINAIS}

Na pesquisa aqui apresentada, foi investigada qual a percepção dos alunos em relação ao modelo de ensino híbrido, incluindo métodos de ensino, recursos didáticos e perfil do professor. Os resultados mostraram que, de acordo com a opinião dos alunos há uma preferência do modelo de ensino tradicional em relação ao modelo de ensino híbrido. Vale destacar que, o perfil do professor não foi um fator que interferiu nessa opinião, pois conforme a opinião dos alunos, os dois professores apresentaram a mesma segurança no conteúdo ministrado.

Quanto à utilização de recursos didáticos, ficou claro que a maioria dos alunos preferiram os recursos utilizados na metodologia tradicional (quadro, pincel e listas de exercícios). Quanto aos instrumentos de 
avaliação, também foi evidenciado que a maioria deles preferiu o teste tradicional como instrumento de avaliação, ao invés dos quizzes e outros instrumentos digitais, pois os alunos acreditam que a prova escrita ainda é o melhor instrumento de avaliação.

Por fim, acredita-se que, para a implementação de um modelo de ensino híbrido, é necessário muito mais do que apenas a utilização de recursos digitais. Portanto, para romper com os paradigmas historicamente estabelecidos, é preciso um planejamento adequado, tanto para familiarizar os alunos com as ferramentas digitais, quanto para incorporá-las no contexto escolar.

\section{REFERÊNCIAS}

ALVES, L. Games, colaboração e aprendizagem. In: Okada, A. (Org.). Open Educational Resources and Social Networks: Co-Learning and Professional Development. London: Scholio Educational Research \& Publishing, 2012. Disponivel em: <http://oer.kmi.open.ac.uk/wp-content/ uploads/cap09_virtuais.pdf>. Acesso em: 26 out. 2016.

BUENO, A. P. ; RITZEL, M. I. A Informática no Contexto Educacional. Revista Conhecimento Online, v. 2, 2013.

CARVALHO, A. A. A. Apps para ensinar e para aprender na era mobile learning. In: Ana Amélia A. Carvalho (Org.). Apps para dispositivos móveis: manual para professores, formadores e bibliotecários. Portugal: Ministério da Educação, 2015. p. 9-17. Disponivel em: <https://estudogeral.sib.uc.pt/jspui/ handle/10316/31202 >. Acesso em: 31 jan. 2017.

CARVALHO, A. M. P. ; GIL PÉREZ, D. O saber e o saber fazer dos professores. In: CASTRO, A. D. e CARVALHO, A. M. P. (Org.). Ensinar a Ensinar: Didática para a Escola Fundamental e Média. São Paulo: Pioneira Thomson Learning, p. 107-124, 2001.

CHRISTENSEN, C.; HORN, M.; STAKER, H. Ensino Híbrido: uma Inovação Disruptiva?. Uma introdução à teoria dos híbridos, 2013. Disponivel em: <https://s3.amazonaws.com/porvir/wp-content/ uploads/2014/08/PT_Is-K-12-blended-learning-disruptive-Final.pdf >. Acesso em: 03 jul. 2017.

DELLOS, R. Kahoot! A digital game resource for learning. International Journal of Instructional Technology And Distance Learning, v. 12, n. 4, p. 49-52, 2015. 
ECK, R. V. Digital Game-Based Learning: It's Not Just the Digital Na Oves Who Are Restless. Educause Review, v. 41, N. 2, p. 16-30, 2006.

FARDO, M. L. A gamificação como estratégia pedagógica: estudo de elementos dos games aplicados em processos de ensino e aprendizagem. Dissertação (Mestrado em Educação) - Programa de PósGraduação em Educação, Universidade de Caxias do Sul, Caxias do Sul, 2013.

JOHNSON, L. et al. Technology Outlook for Brazilian Primary and Secondary Education 2012-2017: An NMC Horizon Project Sector Analysis. Austin, Texas: The New Media Consortium, 2012.

MORAN, J. Mudando a educação com metodologias ativas. In: SOUZA, C. A.; MORALES, O. E. T. (Org.). Coleção Mídias Contemporâneas. Convergências Midiáticas, Educação e Cidadania: aproximações jovens. Ponta Grossa: UEPG/PROEX, p. 15- 33, 2015. Disponivel em: <http://www2.eca.usp. br/moran/ wp-content/uploads/2013/12/mudando_moran.pdf>. Acesso em: 13 fev. 2017.

MOREIRA, M. A. O que é afinal Aprendizagem Significativa? Revista Qurriculum, n.25, p. 29-56, 2012. Disponivel em: <https://qurriculum.webs.ull.es/?p=716>. Acesso em: 31 jan. 2017.

PRENSKY, Marc. Digital natives, digital immigrants part 1. On the horizon, v. 9, n. 5, p. 1-6, 2001. Disponivel em: <http:// www.marcprensky.com/writing/prensky\%20-\%20digital\%20natives,\%20 digital\%20immigrants\%20-\%20part1.pdf >. Acesso em: 01 nov. 2016.

SALES, G. L. QUANTUM: Um Software para Aprendizagem dos Conceitos da Física Moderna e Contemporânea. Dissertação (Mestrado Integrado Profissional em Computação Aplicada) - Diretoria de Pesquisa e Pósgraduação do Centro Federal de Educação Tecnológica, Universidade Estadual do Ceará, Fortaleza/CE, 2005.

SALES, G. L. et al. Gamificação e ensinagem híbrida na sala de aula de Física: metodologias ativas aplicadas aos espaços de aprendizagem e na prática docente. Conexões-Ciência e Tecnologia, v. 11, n. 2, p. 45-52, 2017.

SILVA, J. et al. Mudança Conceitual em Óptica Geométrica Facilitada Pelo Uso de TDIC. In: WORKSHOP DE INFORMÁTICA NA ESCOLA, 21, 2015, Maceió. Anais... Porto Alegre: SBC, 2015, p. 1-17.

SCHROEDER, C. A importância da física nas quatro primeiras séries do ensino fundamental. Revista Brasileira de Ensino de Física, v. 29, n. 1, p. 89-94, 2007.

YIN, R. K. Estudo de caso: planejamento e métodos. 2. ed. Porto Alegre: Bookman, 2001. 